\title{
Correction to: Bioactive Compounds of Prickly Pear [Opuntia ficus-indica (L.) Mill.]
}

Imen Belhadj Slimen, Taha Najar, and Manef Abderrabba

Correction to: Chapter 9, "Bioactive Compounds of Prickly Pear [Opuntia ficus-indica (L.) Mill.]" in: H. N. Murthy, K. Y. Paek (eds.), Bioactive Compounds in Underutilized Vegetables and Legumes, Reference Series in Phytochemistry, https://doi.org/10.1007/978-3-030-57415-4_12

In table 1, missing text has been included in the columns "Cladodes", "Fruits", "Peels" and "Seeds". The spelling of the term "Flavanols" is updated to "Flavonols" in two instances.

The updated online version of this chapter can be found at https://doi.org/10.1007/978-3-030-57415-4_12 